\title{
Polymerization Mechanism in Methyl Methacrylate-Grignard Reagent System. I. Phenylmagnesium Bromide
}

\author{
Isao Ando, Riichirô ChûJô, and Atsuo Nishioka \\ Department of Polymer Engineering, Tokyo Institute of Technology, \\ 12-1, Ookayama 2-Chome, Meguro-ku, Tokyo 152, Japan.
}

(Received October 6, 1969)

\begin{abstract}
The mechanism of stereospecific polymerization in a methyl methacrylateGrignard reagent $\left(\mathrm{C}_{6} \mathrm{H}_{5} \mathrm{MgBr}\right)$ system is studied as a function of polymerization temperature with high-resolution nuclear magnetic resonance (NMR) spectroscopy for obtained polymers. It is found that the maximum temperature during the reaction in our experiments is appropriate for adoption as the polymerization temperature rather than the commonly used setting temperature.

As a result it is found that the mechanism is different at temperatures higher and lower than about $266^{\circ} \mathrm{K}$. Also, the NMR spectra of $\mathrm{C}_{6} \mathrm{H}_{5} \mathrm{MgBr}$ in a deuterated toluene$d_{8}$ are measured over a wide range of temperatures and remarkable change is observed in the vicinity of about $266^{\circ} \mathrm{K}$. It may reflect the above difference in polymerization mechanisms on both sides of about $266^{\circ} \mathrm{K}$.

KEY WORDS Poly(Methyl Methacrylate)/ Polymerization Mechanism / Polymerization Temperature / Penultimate Effect / Grignard Reagent /
\end{abstract}

Ionic polymerization gives out a considerable amount of reaction heat in general and causes variations in temperature between the inside and the outside of the reaction vessel in our system. This throws doubt upon the accuracy of discussing the mechanism of stereospecific polymerization from data prepared as a function of setting temperatures, i.e., the temperatures set up before polymerization, as a measure of polymerization temperatures. In order to clarify this point, a measure of polymerization temperature is sought in this paper, for a system of methyl methacrylate (MMA) and Grignard reagent with the aid of high-resolution nuclear magnetic resonance (NMR) spectroscopy.

Next, the polymerization mechanism in the system is studied by an application of testing formulae for ultimate and penultimate unit effects in the propagation step developed by one of the authors, Chûjô, ${ }^{1}$ on the basis of the information obtained on polymerization temperatures.

This system has been investigated by one of the authors, Nishioka and his colleagues. ${ }^{2,3}$ They found that a wide variety of stereospecificity is obtained by substitution of alkyl groups in Grignard reagents, polymerization temperatures and some effective organic additives. The polymers obtained were classified into highly stereospecific ones and others, but at that time the above-mentioned problem was ignored.

Since Grignard reagents were discovered by Grignard in 1900, there has been considerable work on the species present in solution; a comprehensive review of studies has been made by Kharasch and Reinmuth. ${ }^{4}$ The most widely accepted hypothesis $^{4}$ is in the form of an equilibrium

$$
\mathrm{R}_{2} \mathrm{Mg} \cdot \mathrm{MgX}_{2} \rightleftarrows \mathrm{R}_{2} \mathrm{Mg}+\mathrm{MgX}_{2} \rightleftarrows 2 \mathrm{RMgX}
$$

Although Grignard reagent in solution has been studied by Evans, et al. ${ }^{5,6}$ with the aid of NMR spectroscopy, its exact structure is unknown as yet. Kawabata and Furukawa ${ }^{7}$ studied the relation between microtacticity of poly(methyl methacrylate) (PMMA) prepared with Grignard reagents and the structure of the reagents by an application of the molecular orbital theory and suggested that Grignard reagent behaves as an $\mathrm{RMgX}$ form at higher temperatures and as an $\mathrm{R}_{2} \mathrm{Mg}$ form at lower temperatures. Our object is also to investigate the temperature 
dependence of the behavior of Grignard reagent in solution with the aid of NMR spectroscopy. The results of temperature dependences of microtacticity of both the polymers obtained and the Grignard reagents are compared.

\section{EXPERIMENTAL}

\section{Material}

Solvents used were purified by the usual method. ${ }^{8}$ A toluene solution of phenylmagnesium bromide was prepared by a method described elsewhere ${ }^{2}$ and a toluene solution of diphenylmagnesium was also prepared using a method described elsewhere. ${ }^{9}$ The concentrations of phenylmagnesium bromide and diphenylmagnesium were determined by NMR. MMA was purified by several washings with $10 \%$ aqueous solutions of sodium hydroxide, followed by repeated washings with water. After being dried with anhydrous sodium sulfate, it was distilled in vacuo.

\section{Method of Polymerization}

The polymerization apparatus used is shown in Figure 1. A toluene solution of the catalyst $(10 \mathrm{ml})$ was placed in reaction vessel (A) $(100 \mathrm{ml})$ and a mixture of the monomer $(10 \mathrm{ml})$ and toluene $(10 \mathrm{~m} l)$ in vessel $(B)(100 \mathrm{ml})$ in a dry box containing nitrogen. A thermocouple was sealed into a glass tube (C). The contents of the vessels (A) and (B) were kept at the same constant temperature, and the content of (B)

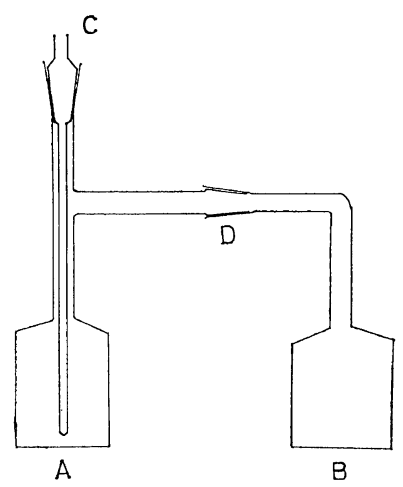

Figure 1. Apparatus for polymerization; A, vessel in which the catalyst is charged; $\mathbf{B}$, vessel in which the monomer and toluene are charged; $\mathrm{C}$, glass tube in which thermocouple is sealed, $\mathrm{D}$, rotating joint. was transferred into (A) as rapidly as possible by the rotation of a joint (D) in order to start the polymerization.

The change in temperature due to the heat of polymerization was measured by an alumelchromel thermocouple placed in the reaction vessel (A). The signals from the thermocouple were amplified and recorded on chart paper with a pen recorder.

\section{Measurement of NMR}

Microtacticity of PMMA was determined by NMR spectroscopy. Measurements for PMMA polymerized with phenylmagnesium bromide were made with a JNM-4H-100 spectrometer operated at $100 \mathrm{MHz}$ and those for PMMA with diphenylmagnesium were made with a JNM-C$60 \mathrm{H}$ operated at $60 \mathrm{MHz}$. Both sets of measurements were carried out at $393^{\circ} \mathrm{K}$ in nitromethane, the concentration of the sample solution being $6 \%$. Measurements for degassed solutions of deuterated toluene- $d_{8} \quad\left(\mathrm{C}_{6} \mathrm{D}_{5} \mathrm{CD}_{3}\right)$ or phenylmagnesium bromide and diphenylmagnesium were made with a JNM-C-60H spectrometer operated at $60 \mathrm{MHz}$, tetramethylsilane (TMS) being used as an internal reference. The concentration of the solution was $13 \%$.

\section{RESULTS AND DISCUSSION}

\section{Microtacticity of PMMA}

Although the setting temperatures have been generally accepted as polymerization temperatures except in a few papers, it is doubtful whether it is valid to do so because of the considerable amount of heat resulting from the polymerization reaction. A record of the change of temperature in the reaction vessel

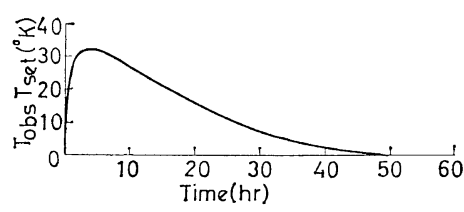

Figure 2. A typical record of the change of temperature $\left(T_{\mathrm{obs}}\right)$ in the reaction vessel against time with reference to the setting temperature: $\left(T_{\text {set }}\right)$ : setting temperature, $273^{\circ} \mathrm{K}$; maximum temperature, $307.5^{\circ} \mathrm{K}$; concentration of $\mathrm{C}_{6} \mathrm{H}_{5} \mathrm{MgBr}$, $2.53 \times 10^{-3} \mathrm{~mol} \mathrm{l}^{-1}$; concentration of methyl methacrylate, $32 \mathrm{~mol} l^{-1}$. 
Polymerization Mechanism in MMA-Grignard

Table I. Microtacticity for PMMA prepared with $\mathrm{C}_{6} \mathrm{H}_{5} \mathrm{MgBr}$

\begin{tabular}{|c|c|c|c|c|c|c|c|c|c|c|c|}
\hline \multirow{3}{*}{ Samples } & \multirow{3}{*}{$\begin{array}{c}\text { Setting } \\
\text { temp, } \\
{ }^{\circ} \mathrm{K}\end{array}$} & \multirow{3}{*}{$\begin{array}{c}\text { Maximum } \\
\text { temp, } \\
{ }^{\circ} \mathrm{K}\end{array}$} & \multirow{3}{*}{$\begin{array}{c}\text { Catalyst, } \\
\text { mol } l^{-1} \\
\times 10^{3}\end{array}$} & \multicolumn{3}{|c|}{ Polymerization } & \multicolumn{5}{|c|}{ Microtacticity } \\
\hline & & & & \multirow{2}{*}{$\begin{array}{l}\text { MMA, } \\
\text { mol } l^{-1}\end{array}$} & \multirow{2}{*}{$\underset{\text { min }}{\text { Time, }}$} & \multirow{2}{*}{$\begin{array}{l}\text { Conver- } \\
\text { sion, } \%\end{array}$} & \multicolumn{3}{|c|}{ Triads } & \multicolumn{2}{|c|}{$\overline{\text { Dyads }}$} \\
\hline & & & & & & & $I, \%$ & $H, \%$ & $S, \%$ & $i, \%$ & $s, \%$ \\
\hline $0-3$ & 263 & 316 & 6.00 & 32 & 46 & 38 & 94.45 & 2.72 & 1.83 & 96.81 & 3.19 \\
\hline $0-5$ & 273 & 307.5 & 2.53 & 32 & 2.5 & 16 & 93.75 & 4.16 & 2.09 & 95.83 & 4.27 \\
\hline $0-4$ & 273 & 305 & 2.53 & 32 & 62.5 & 20 & 93.55 & 4.02 & 2.43 & 95.56 & 4.44 \\
\hline $0-2$ & 243 & 305 & 10.00 & 32 & 3.5 & 33 & 93.68 & 4.21 & 2.11 & 95.78 & 4.22 \\
\hline $0-1$ & 243 & 293 & 6.00 & 32 & 44 & 24 & 92.87 & 4.45 & 2.55 & 94.65 & 5.35 \\
\hline N0-4 & 245 & 267 & 1.40 & 32 & 20 & 14 & 84.00 & 7.34 & 8.66 & 87.67 & 12.33 \\
\hline N0-1 & 233 & 265 & 2.53 & 32 & 17 & 4.5 & 73.88 & 8.96 & 17.16 & 78.36 & 21.64 \\
\hline No-3 & 223 & 243 & 1.40 & 32 & 89 & 3 & 67.11 & 12.09 & 20.80 & 73.14 & 26.86 \\
\hline DE-1 & 195 & 203 & 1.00 & 32 & 3000 & 2 & 48.40 & 16.10 & 35.50 & 56.45 & 43.55 \\
\hline
\end{tabular}

after the transfer of the contents of (B) into (A) is shown in Figure 2. As seen from this figure, the temperature in the vessel was raised to $305^{\circ} \mathrm{K}$ (maximum temperature) from $273^{\circ} \mathrm{K}$ (setting temperature) 2.5 minutes after transfer. Fifty minutes elapsed before return to the setting temperature. In ascertaining the polymerization temperature the polymerization system in the vessel was not stirred so that heat loss due to thermal diffusion would be prevented. This demonstrates the inadequacy of adopting the setting temperature as a polymerization temperature.

Polymerization conditions and microtacticities of samples are listed in Table I. It was found that microtacticities are affected by the maximum temperatures rather than the setting ones for the following reasons; (1) in experiments $0-2$ and $0-4$ the setting temperatures differ by $30^{\circ} \mathrm{K}$; the maximum ones coincide, while the microtacticities practically coincide, and (2) in experiments $0-1$ and $\mathrm{N} 0-4$ the setting temperatures are nearly equal and the maximum ones differ by $26^{\circ} \mathrm{K}$ while the microtacticities are significantly different. Experiment $0-5$ was carried out in order to ascertain whether such maximum temperatures reflect the characteristics of the propagation mechanism. This experiment corresponded to that of $0-4$ in polymerization conditions except for the polymerization time. The polymerization in the former was stopped at the time a maximum temperature was reached in the latter. Both conversions are nearly equal. Thus it is found that the conversions depend on the maximum temperatures rather than polymerization times. Microtacticities in both experiments coincide fairly well with each other. Therefore the maximum temperature is appropriate for adoption as the polymerization temperature in our experiments rather than the commonly used setting temperature. The microtacticities in the PMMA obtained are plotted against these maximum and setting temperatures in Figure 3. (There is a considerable scattering

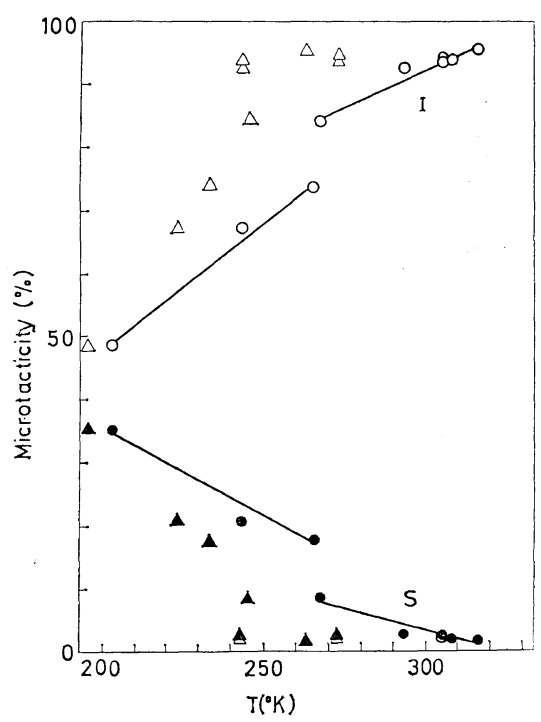

Figure 3. Temperature dependence of microtacticity (triads) for PMMA prepared with $\mathrm{C}_{6} \mathrm{H}_{5} \mathrm{MgBr}$. Maximum temperature $(\bigcirc$, isotactic; syndiotactic); setting temperature $(\triangle$, isotactic, $\Delta$, syndiotactic). 
from linearity of the points for plots to the setting temperatures, while the points to the maximum temperatures lie on either of two straight lines corresponding to higher and lower temperatures. If we try to obtain two similar straight lines for the data of microtacticities against the setting temperatures, we reach a two-valued function which must be abandoned.) A small gap appears at about $266^{\circ} \mathrm{K}$ in the plots of both isotacticity $(I)$ and syndiotacticity $(S)$ in Figure 3 against the maximum temperatures. We conjecture that the propagation mechanisms of stereospecific polymerizations are different in the ranges of higher and lower temperatures. We, therefore, treated these mechanisms with expressions ${ }^{1,10}$ which test the reality of the ultimate and penultimate effects, and evaluated their magnitudes.

Furukawa $^{10}$ has derived an expression, which evaluates the magnitude of ultimate effect in stereospecific polymerization, as follows:

$$
\Delta \varepsilon_{u}=H_{u}-T \Delta S_{u}=-k T \ln (I / S)
$$

where $\Delta \varepsilon_{u}, \Delta H_{u}$ and $\Delta S_{u}$ are contributions from the ultimate unit to the difference of activated free energy, enthalpy and entropy, respectively, between isotactic and syndiotactic placements, $k$ being the Boltzmann constant and $T$ the polymerization temperature in Kelvin. $\Delta \varepsilon_{u}$ 's are plotted against $T$ in Figure 4 . The abscissa is, of course, the maximum temperature. These plots produce two straight lines in this case also corresponding to higher and lower temperatures.

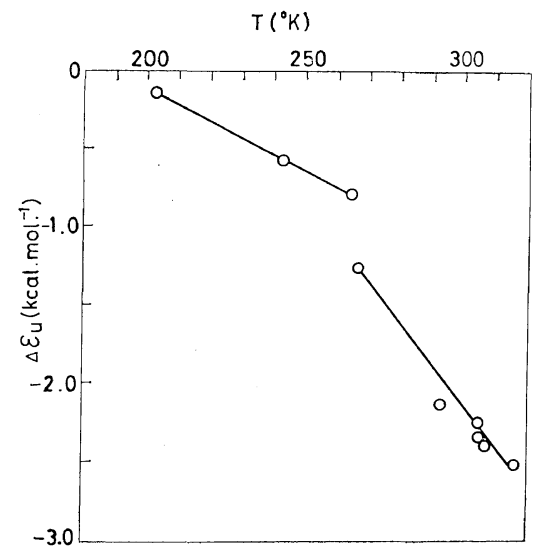

Figure 4. The plot of $\Delta_{\varepsilon_{u}} v s . T$ for PMMA prepared with $\mathrm{C}_{6} \mathrm{H}_{5} \mathrm{MgBr}$.
The differences of activated enthalpies and entropies can be calculated, respectively, from the intersect and the slope of each line at higher and lower temperatures as follows:

$$
\begin{gathered}
\text { Higher temperatures }\left(\gtrsim 266^{\circ} \mathrm{K}\right) \\
\Delta H_{u}=5.8 \pm 0.2 \mathrm{kcal} \mathrm{mol}^{-1} \\
\Delta S_{u}=26.6 \pm 0.8 \mathrm{e} . \mathrm{u} .
\end{gathered}
$$

Lower temperatures $\left(\leq 266^{\circ} \mathrm{K}\right)$

$$
\begin{aligned}
& \Delta H_{u}=2.1 \pm 0.1 \mathrm{kcal} \mathrm{mol}^{-1} \\
& \Delta S_{u}=10.9 \pm 0.5 \mathrm{e.u} .
\end{aligned}
$$

It may be concluded that the differences of both activated enthalpies and entropies are greater at higher temperatures than those at lower temperatures.

Next, the contribution by the penultimate unit to the propagation mechanism is considered with the aid of the following expression to test the reality of such contribution, as proposed by Chûjố ${ }^{1 !}$.

$$
\Delta \varepsilon_{p}=\Delta H_{p}-T \Delta S_{p}=-k T \ln \frac{4 I S}{H_{z}}
$$

where $\Delta \varepsilon_{p}, \Delta H_{p}$ and $\Delta S_{p}$ are contributions from the penultimate unit to the differences in activated free energy, enthalpy and entropy, respectively. If $I, H$ or $S$ approach zero in value, $\Delta \varepsilon_{p}$ may become enumerous. The equations of the straight lines in Figure 3 are derived by the method of least squares and the values of $\Delta \varepsilon_{p}$ are calculated by interpolated value from

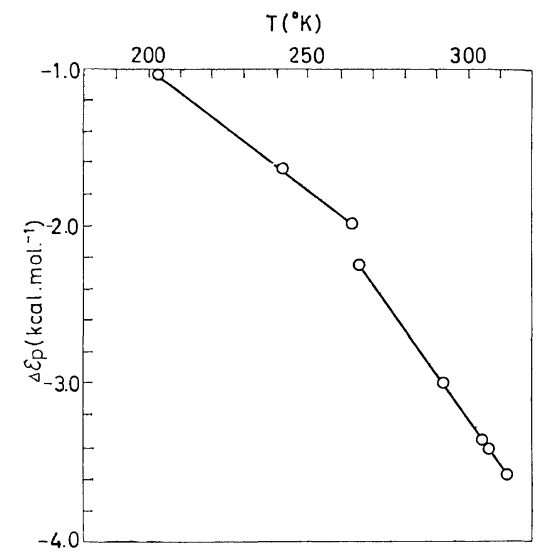

Figure 5. The plot of $\Delta \varepsilon_{p} v s . T$ for PMMA prepared with $\mathrm{C}_{6} \mathrm{H}_{5} \mathrm{MgBr}$; from the value corresponding to the straight line in Figure 3. 
the equations derived. $\Delta \varepsilon_{p}$ 's are plotted against polymerization temperatures for this system in Figure 5. $\Delta H_{p}$ and $\Delta S_{p}$ were calculated from the intersect and the slope of each of two straight lines in Figure 5 corresponding to higher and lower temperatures, respectively, as follows;

$$
\begin{gathered}
\text { Higher temperatures }\left(\gtrsim 266^{\circ} \mathrm{K}\right) \\
\Delta H_{p}=2.0 \pm 0.0 \mathrm{kcal} \mathrm{mol}^{-1} \\
\Delta S_{p}=25.0 \pm 2.0 \mathrm{e} . \mathrm{u} .
\end{gathered}
$$

Lower temperatures $\left(\lessgtr 266^{\circ} \mathrm{K}\right)$

$$
\begin{aligned}
& \Delta H_{p}=0.5 \pm 0.0 \mathrm{kcal} \mathrm{mol}^{-1} \\
& \Delta S_{p}=15.1 \pm 1.1 \text { e.u. }
\end{aligned}
$$

We polymerized MMA in toluene with $\left(\mathrm{C}_{6} \mathrm{H}_{5}\right)_{2} \mathrm{Mg}$, a substance which appeared in eq 1 as a possible form of $\mathrm{C}_{6} \mathrm{H}_{5} \mathrm{MgBr}$. The results of its microtacticities are shown in Table II. The polymerization was carried out by a method similar to that described above. In this case as the heat of polymerization is not fully dissipated, both the maximum and setting temperatures may be used as polymerization temperatures. The temperature dependence on microtacticities for the polymers prepared with $\left(\mathrm{C}_{6} \mathrm{H}_{5}\right)_{2} \mathrm{Mg}$ is shown in Figure 6. The contents of three triads are comparable with one another and they are similar to those in the case of $\mathrm{C}_{6} \mathrm{H}_{4} \mathrm{MgBr}$ at lower temperatures. It is found from Tables I and II that the conversions of the samples prepared with Grignard reagent $\left(\mathrm{C}_{6} \mathrm{H}_{5} \mathrm{MgBr}\right)$ in temperatures lower than about $266^{\circ} \mathrm{K}$ are much lower than those in higher temperatures (although there is some doubt because of the varying concentrations of the catalysts). Such behavior may correspond to the difference of the polymerization mechanism at temperatures higher and lower than about $266^{\circ} \mathrm{K}$, and that the con- versions in lower temperatures are similar to those of the samples prepared with $\left(\mathrm{C}_{6} \mathrm{H}_{5}\right)_{2} \mathrm{Mg}$. Therefore we may suggest that $\left(\mathrm{C}_{6} \mathrm{H}_{5}\right)_{2} \mathrm{Mg}$ exists as a possible form in equilibrium of eq 1 in a toluene solution of $\mathrm{C}_{6} \mathrm{H}_{5} \mathrm{MgBr}$ at lower temperatures. $\Delta \varepsilon_{p}$ 's are plotted against the polymerization temperature for this system in Figure 7 and the differences of activated enthalpy and entropy become as follows

$$
\begin{aligned}
& \Delta H_{u}=0.7 \pm 0.0 \mathrm{kcal} \mathrm{mol}^{-1} \\
& \Delta S_{u}=2.0 \pm 0.2 \mathrm{e} . \mathrm{u} .
\end{aligned}
$$

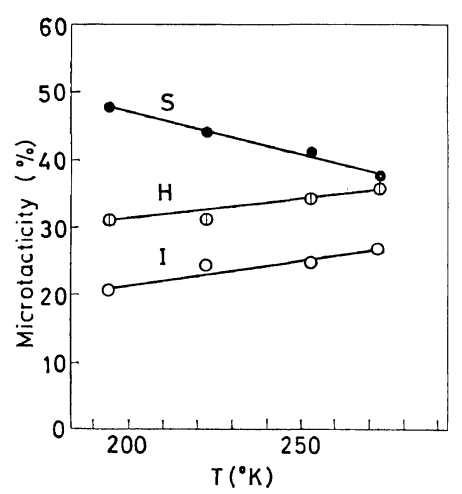

Figure 6. Temperature dependence of microtac-

\begin{tabular}{|c|c|c|c|c|c|c|c|c|c|c|}
\hline \multirow{3}{*}{ Samples } & \multirow{3}{*}{$\begin{array}{c}\text { Poly- } \\
\text { meriza- } \\
\text { tion } \\
\text { Temp } \\
\mathbf{K}^{\circ}\end{array}$} & \multirow{3}{*}{$\begin{array}{c}\text { Catalyst } \\
\text { mol, } \\
1 \times 10^{3}\end{array}$} & \multicolumn{3}{|c|}{ Polymerization } & \multicolumn{5}{|c|}{ Microtacticity } \\
\hline & & & \multirow{2}{*}{$\begin{array}{l}\text { MMA, } \\
\text { mol } l^{-1}\end{array}$} & \multirow{2}{*}{ Time, } & \multirow{2}{*}{$\begin{array}{l}\text { Conver- } \\
\text { sion, } \\
\%\end{array}$} & \multicolumn{3}{|c|}{ Triads } & \multicolumn{2}{|c|}{ Dyads } \\
\hline & & & & & & $I, \%$ & $H, \%$ & $S, \%$ & $i, \%$ & $s, \%$ \\
\hline $\mathrm{J}-1$ & 293 & 1.7 & 32 & 5.0 & 5 & 26.63 & 35.80 & 37.57 & 44.53 & 55.47 \\
\hline $\mathrm{J}-4$ & 253 & 1.7 & 32 & 6.0 & 6 & 24.61 & 34.08 & 41.31 & 41.65 & 58.35 \\
\hline $\mathrm{J}-3$ & 223 & 1.7 & 32 & 2.5 & 4.5 & 24.36 & 31.62 & 44.02 & 40.17 & 59.83 \\
\hline $\mathrm{J}-2$ & 195 & 1.7 & 32 & 4.0 & 4 & 20.84 & 31.42 & 47.74 & 36.55 & 63.45 \\
\hline
\end{tabular}
ticity (triads) for PMMA prepared with $\left(\mathrm{C}_{6} \mathrm{H}_{5}\right)_{2} \mathrm{Mg}$ : $\bigcirc$, isotactic; $(1)$, heterotactic; $\bullet$, syndiotactic.

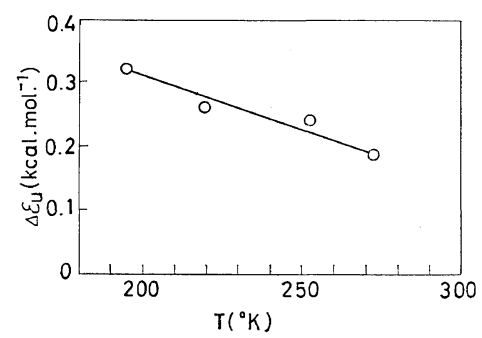

Figure 7. The plot of $\Delta_{\varepsilon u} v s . T$ for PMMA prepared with $\left(\mathrm{C}_{6} \mathrm{H}_{5}\right)_{2} \mathrm{Mg}$.

Table II. Microtacticity for PMMA prepared with $\left(\mathrm{C}_{6} \mathrm{H}_{5}\right)_{2} \mathrm{Mg}$ 


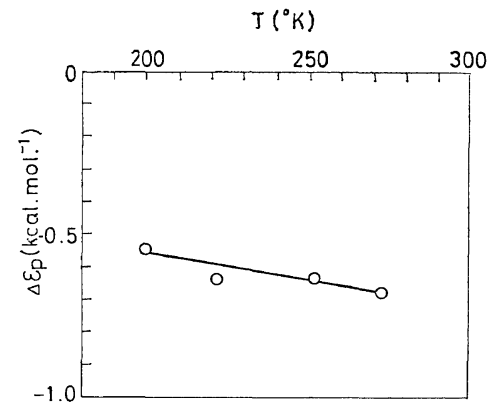

Figure 8. The plot of $\Delta \varepsilon_{p} v s . T$ for PMMA prepared with $\left(\mathrm{C}_{6} \mathrm{H}_{5}\right)_{2} \mathrm{Mg}$.

These values are kept as constants for a wide range of temperatures, and a critical temperature such as $266^{\circ} \mathrm{K}$ in the system with $\mathrm{C}_{6} \mathrm{H}_{5} \mathrm{MgBr}$ is not observed.

$\Delta \varepsilon_{p}$ 's are plotted against the polymerization temperature for this system in Figure 8 and $\Delta H_{p}$ and $\Delta S_{p}$ become as follows

$$
\begin{aligned}
& \Delta H_{p}=-0.2 \pm 0.0 \mathrm{kcal} \mathrm{mol}^{-1} \\
& \Delta S_{p}=2.7 \pm 0.0 \mathrm{e} . \mathrm{u} .
\end{aligned}
$$

These values, also, are kept as constants for a wide range of temperatures and a gap is not observed.

\section{NMR Spectra of Grignard Reagents}

For investigating in detail the mechanism of stereospecific polymerization in which a small gap is observed in the vicinity of about $266^{\circ} \mathrm{K}$, we studied the NMR spectra of Grignard reagents $\left(\mathrm{C}_{6} \mathrm{H}_{5} \mathrm{MgBr}\right.$ and $\left.\left(\mathrm{C}_{6} \mathrm{H}_{5}\right)_{2} \mathrm{Mg}\right)$ over a wide range of temperatures.

We first measured the NMR spectra $(60 \mathrm{MHz})$ of toluene- $d_{8}$ solution of $\mathrm{C}_{6} \mathrm{H}_{5} \mathrm{MgBr}$ from $216^{\circ} \mathrm{K}$ to $329^{\circ} \mathrm{K}$ using the same equipment as in the preceding section. The spectra are reproduced in Figures $9 \mathrm{a}$ and $\mathrm{b}$. Every spectrum consists of two signals (Hereafter, we denote them A and $B$ signals as shown in Figure $9 a$ and $\mathbf{b}$. A and B signals are assigned to the ortho- and para- protons, and the meta-protons, respectively, in comparison with the numerical values for proton chemical shifts in monosubstituted benzenes. ${ }^{11)}$ The ratios of $\mathrm{A} / \mathrm{B}$, however, deviated from the theoretical value (1.5) under the above assignment of $\mathrm{A}$ and $\mathrm{B}$ signals. Therefore, we may conjecture a complicated form in the Grignard reagent $\left(\mathrm{C}_{6} \mathrm{H}_{5} \mathrm{MgBr}\right)$ in solution.

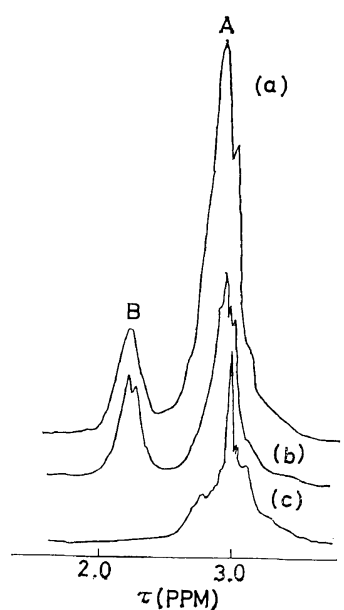

Figure 9. NMR spectra of Grignard reagents: (a) $13 \%$ solution of $\mathrm{C}_{6} \mathrm{H}_{5} \mathrm{MgBr}$ in toluene- $d_{8}$ at $263^{\circ} \mathrm{K}$; (b) $13 \%$ solution of $\mathrm{C}_{6} \mathrm{H}_{5} \mathrm{MgBr}$ in toluene- $d_{8}$ at $273^{\circ} \mathrm{K}$; (c) $13 \%$ solution of $\left(\mathrm{C}_{6} \mathrm{H}_{5}\right)_{2} \mathrm{Mg}$ in toluene- $d_{8}$ at $263^{\circ} \mathrm{K}($ at $60 \mathrm{MHz})$.

The NMR spectrum of $\left(\mathrm{C}_{6} \mathrm{H}_{5}\right)_{2} \mathrm{Mg}$, shown in Figure $9 \mathrm{c}$ is remarkably different from that of Figure $9 a$ and $b$, that is, all the signals of the former almost coincide with the range of the A signal. If we recall that the values of $\mathrm{A} / \mathrm{B}$ are larger than the theoretical value (1.5), it may be considered that the A signal is partly contributed to by $\left(\mathrm{C}_{6} \mathrm{H}_{5}\right)_{2} \mathrm{Mg}$. Further, the fact thatthere did not appear to be a large chemical shift in the ortho-, meta- and para protons of $\mathrm{R}_{2} \mathrm{Mg}$, may suggest the homopolar character of this compound. The ratios of $\mathrm{A} / \mathrm{B}$ are plotted against temperatures in Figure 10. A gap is observed between 263 and $273^{\circ} \mathrm{K}$. This gap corresponds to the gap in the vicinity of about $266^{\circ} \mathrm{K}$ in polymerization by $\mathrm{C}_{6} \mathrm{H}_{5} \mathrm{MgBr}$. There-

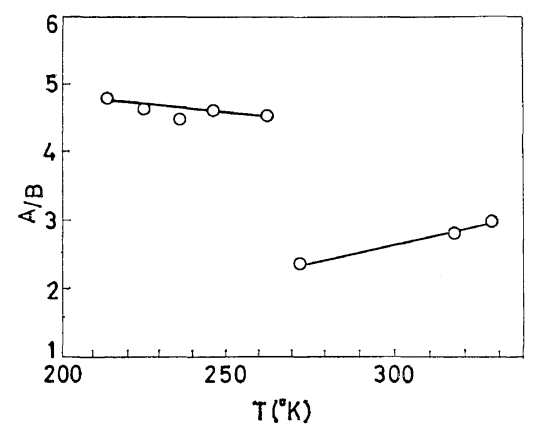

Figure 10. The plot of the ratios of A/B vs. T. 
fore, the forms of the catalyst in toluene- $d_{8}$ solution are different from each other between the ranges of temperatures higher and lower than the temperature lying between 263 and $273^{\circ} \mathrm{K}$. The ratios of $\mathrm{A} / \mathrm{B}$ at higher temperatures lie about 2.5 , but at lower temperatures lie about 4.5. Therefore, it is found that the catalysts at higher and lower temperatures have much more heteropolar and hemopolar bonds between the $\mathrm{Mg}$ atom and the phenyl group, respectively. The catalyst $\mathrm{C}_{6} \mathrm{H}_{5} \mathrm{MgBr}$ reacts at lower temperatures in the form of $\left(\mathrm{C}_{6} \mathrm{H}_{5}\right)_{2} \mathrm{Mg}$ which contains a rather homopolar bond between the $\mathrm{Mg}$ atom and the phenyl group. By the use of the extended Hückel method, it is known that Grignard reagents behave as $\mathrm{RMgX}$ forms at higher temperatures. ${ }^{7}$ We cannot define at this stage the nature of the structure of the catalyst at higher temperatures. However, if it is proved that the bond between $\mathbf{R}$ and $\mathbf{M g}$ is certainly heteropolar, our experimental results also coincide with the $\mathrm{RMgX}$ form of the catalyst. In addition, the fact that the gap in Figure 10 corresponds to the one in the vicinity of $266^{\circ} \mathrm{K}$ in polymerization by $\mathrm{C}_{6} \mathrm{H}_{5} \mathrm{MgBr}$, supports the adoption of the maximum temperature as the polymerization temperature. Actually, the form of the catalyst during the polymerization may differ from that of the catalyst in toluene because of the different circumstances in these two systems. We did not obtain any specific information on the form of the catalyst during polymerization. We shall estimate the form of the catalyst during polymerization on the basis of knowledge of the form of the catalyst in toluene. It is of interest, however, that the gap in Figure 3 appeared in the same temperature region as in Figure 10. We can say that Grignard reagent behaves as the $\mathrm{R}_{2} \mathrm{Mgt}$ form at lower temperatures and also that it is possible this reagent behaves as the $\mathrm{RMgX}$ form at higher temperatures. We shall discuss these problems in more detail in the near future.

\section{CONCLUSION}

We may conclude as follows: (1) The maximum temperature during reaction in our experiments is appropriate for adoption as the polymerization temperature, rather than the commonly used setting temperature. (2) The mechanism of stereospecific polymerization in the MMA-Grignard reagent $\left(\mathrm{C}_{6} \mathrm{H}_{5} \mathrm{MgBr}\right)$ system is different between higher and lower temperatures, corresponding to the remarkable change in the behavior of the Grignard reagent $\left(\mathrm{C}_{6} \mathrm{H}_{5} \mathrm{MgBr}\right)$ in a deuterated toluene- $d_{8}$, (3) The catalyst reacts at lower temperatures in the $\left.\left(\mathrm{C}_{6} \mathrm{H}_{5}\right)_{2} \mathrm{Mg}\right)$ form and (4) the form of the catalyst at higher temperatures is not clear at this stage.

\section{REFERENCES}

1. R. Chûjô, J, Phys. Soc. Japan, 21, 2669 (1966).

2. A. Nishioka, H. Watanabe, K. Abe, and Y. Sono, J. Polym. Sci., 48, 241 (1940).

3. Y. Kato, H. Watanabe, and A. Nishioka, Bull. Chem. Soc. Japan, 37, 1630 (1964).

4. M. S. Kharasch and O. Reinmuth, "Grignard Reagents of Nonmetallic Substances," PrenticeHall, Inc., New, N. Y. 1954.

5. D. F. Evans and J. P. Maher, J. Chem. Soc., 5152 (1962).

6. D. F. Evans and M. S. Khan, Chem. Comm., 3, 67 (1966).

7. H. Kawabata and J. Furukawa, Kogyo Kagaku Zasshi (J. Chem. Soc. Japan, Chem. Ind. Sect.), 70, 1423 (1967).

8. A. Weissberger and E.S. Proskauer, "Organic Solvents," Interscience Pub., Inc., New York, N. Y. 1954.

9. J. Furukawa, T. Tsuruta, T. Fueno, S. Inoue, N. Kawabata, K. Onishi, and T. Saegusa, Kogyo Kagaku Zasshi (J. Chem. Soc. Japan, Chem. Ind. Sect.), 61, 723 (1958).

10. J. Furukawa, Kobunshi (High Polymers), 16, 520 (1967).

11. H. Spiesecke and W. G. Schneider, J. Chem. Phys., 35, 731 (1961). 